\title{
Comment
}

\section{The Decrease in Growth Hormone (GH) Response after Repeated Stimulation with GH-Releasing Hormone Is Partly Caused by an Elevation of Somatostatin Tonus*}

\author{
BARBEL REICHARDT, MONIKA SCHRADER, JURAJ MOJTO, \\ GERHARD MEHLTRETTER $\dagger$, OTTO-ALBRECHT MÜLLER $\ddagger$, AND \\ JOCHEN SCHOPOHL \\ Medizinische Klinik, Klinikum Innenstadt der Ludwig-Maximilians-Universität, Munich, Germany
}

\begin{abstract}
Repeated injection of GHRH leads to a decrease in the GH response in normal subjects. Arginine (Arg) stimulates GH secretion by suppression of hypothalamic somatostatin. To confirm these findings, eight normal men were examined in a series of five settings: test 1 (GHRH/GHRH-TRH), $100 \mu \mathrm{g}$ GHRH injected iv, followed by $100 \mu \mathrm{g}$ GHRH, iv, after $120 \mathrm{~min}$ and $200 \mu \mathrm{g}$ TRH, iv, after $150 \mathrm{~min}$; test 2 (GHRH/Arg-TRH), like test 1, but instead of the second GHRH injection, a $30 \mathrm{~g}$ Arg infusion over $30 \mathrm{~min}$; test 3 (GHRH/GHRH-ArgTRH), like test 1 , but additionally a $30 \mathrm{~g}$ Arg infusion after $120 \mathrm{~min}$; test 4 (GHRH-Arg-TRH), iv GHRH and Arg infusion initially, followed by iv TRH after $30 \mathrm{~min}$; and test 5 (TRH), $200 \mu \mathrm{g} \mathrm{TRH}$, iv, at $0 \mathrm{~min}$.

For statistical evaluation, the area under the GH curve (AUC) from 0-120 min was compared with the AUC from 120-240 min. The GH response to the second administration of GHRH was significantly lower $(P<0.02)$ than the first increase [AUC, $0.5 \pm 0.1 \mathrm{~min} \cdot \mathrm{mg} / \mathrm{L}$ (mean $\pm \mathrm{SE}$ ) vs. $1.2 \pm 0.3]$. No significant differences were found
\end{abstract}

between the GH responses to either GHRH or Arg alone (AUC, $0.9 \pm$ $0.2 \mathrm{~min} \cdot \mathrm{mg} / \mathrm{L}$ vs. $0.9+0.2)$. A larger $\mathrm{GH}$ increase $(P<0.02)$ was seen after GHRH-Arg compared to GHRH alone (AUC, $1.9 \pm 0.4 \mathrm{~min} \cdot \mathrm{mg} / \mathrm{L}$ vs. $1.2 \pm 0.3)$. The GH response $(P<0.02)$ to GHRH-Arg stimulation was lower after previous GHRH injection than after GHRH-Arg stimulation alone (AUC, $1.9 \pm 0.4 \mathrm{~min} \cdot \mathrm{mg} / \mathrm{L}$ vs. $3.5 \pm 0.9$ ). There was a statistically significant difference between the TRH-stimulated TSH response in test 4 compared to that in test 5 . We could show that decreasing $\mathrm{GH}$ responses to repeated GHRH can be avoided by a combined stimulation with GHRH/Arg. These findings suggest that the decreased GH response to a second GHRH bolus may be partly due to an elevated hypothalamic somatostatin secretion, which can be suppressed by Arg. The lower GH response to GHRH-Arg stimulation after a previous GHRH bolus suggests, furthermore, that the readily available GH pool in the human pituitary may be limited. ( $J$ Clin Endocrinol Metab 81: 1994-1998, 1996)
$\mathrm{G}$ H SECRETION is controlled by the hypothalamus via GHRH and its inhibitory opponent, somatostatin (1). Acute injection of GHRH stimulates GH secretion in both normal subjects $(2,3)$ and acromegalic patients $(4,5)$. Continuous GHRH infusion fails to sustain elevated GH levels, and pulsatile stimulation with GHRH also leads to decreasing GH response in normal subjects (6). It was suggested that two different mechanisms may be responsible for these findings; possibly, there is a limitation of GH release from the pituitary on short term stimulation with GHRH due to partial depletion of intracellular GH stores (7), or the stimulation of GH secretion by GHRH may be antagonized by somatostatin secretion from the hypothalamus. As the half-life of somatostatin is extremely short (8), and somatostatin is also produced in the

Received January 10, 1995. Revision received September 14, 1995. Accepted December 19, 1995.

Address all correspondence and requests for reprints to: Dr. Jochen Schopohl, Medizinische Klinik, Klinikum Innenstadt der LMU, Ziemssenstrasse 1, 80336 Munich, Germany.

* Presented in part at the 35th Annual Meeting of the German Endocrine Society, February 27 to March 2, 1991, Bonn, Germany. This work was supported by the Deutsche Forschungsgemeinschaft $(\mathrm{Mu}$ $585 / 3-3)$.

t Present address: Kreiskrankenhaus Freising, Freising, Germany. $\ddagger$ Present address: Krankenanstalten Rotes Kreuz, Munich, Germany. pancreas and gut, somatostatin levels in peripheral blood do not reflect any fluctuations of its concentration in the portal circulation. Arginine (Arg) stimulates GH secretion by suppressing hypothalamic somatostatin (9), allowing indirect conclusions about the hypothalamic somatostatin tonus.

The following study on Arg application was designed to determine whether decreases in GH release after repeated stimulation by GHRH are due to exhaustion of the readily releasable GH pool in human pituitary or whether the GH secretion is specifically suppressed by increasing portal levels of somatostatin.

\section{Materials and Methods}

We studied eight healthy men (mean age, 26.3 yr; range, 19-33), all of normal height, within $15 \%$ of the ideal body weight, and taking no medication known to interfere with GH secretion. The volunteers agreed to participate in the study and gave informed consent in written form. The men were studied in a randomized fashion in a series of five different settings separated by at least 7 days (Fig. 1). All tests were performed in the morning between 0830 and $0900 \mathrm{~h}$ after an overnight fast. An antecubital venous catheter was placed and kept patent by slow saline infusion. The volunteers remained recumbent throughout the test. The experiments satisfied the ethical precepts of the responsible committee on human experimentation and of the Helsinki Declaration. 
FIG. 1. Procedures of tests $1,2,3,4$, and 5. All injections were given iv (GHRH, $100 \mu \mathrm{g}$; TRH, $200 \mu \mathrm{g}$; Arg, $30 \mathrm{~g}$ as an infusion over $30 \mathrm{~min}$ ).
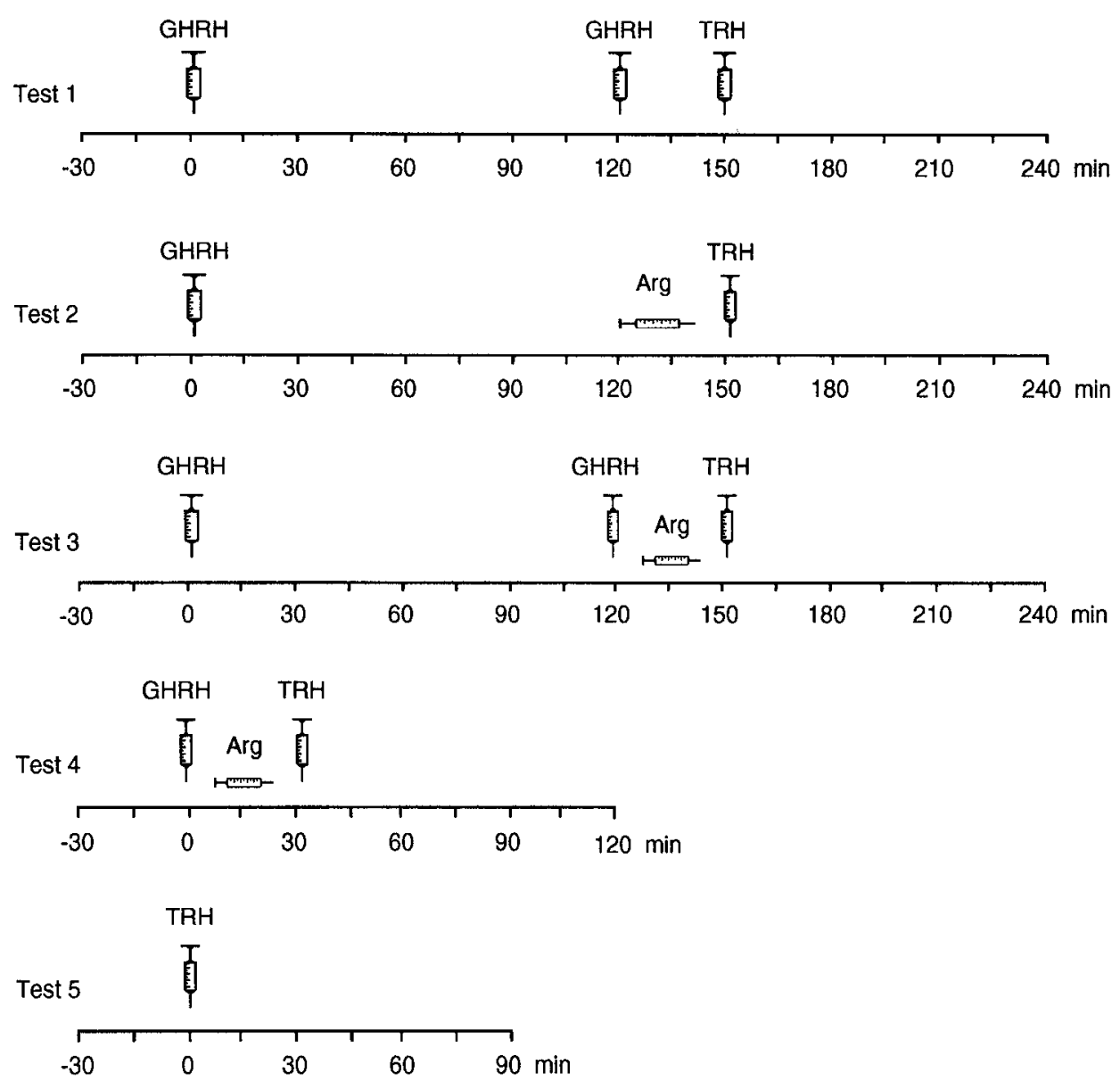

\section{Test 1 (GHRH/GHRH-TRH)}

After a stabilization period of $30 \mathrm{~min}$, the volunteers were given an iv bolus of $100 \mu \mathrm{g}$ GHRH-(1-44) (Somatobiss, Bissendorf Biochemicals, Bissendorf bei Hannover, Germany) over $30 \mathrm{~s}$. After $120 \mathrm{~min}$, this procedure was repeated. After $150 \mathrm{~min}, 200 \mu \mathrm{g}$ TRH (Relefact TRH 200, Hoechst, Bad Soden, Germany) were injected iv. Blood samples were drawn at intervals of 15 or $30 \mathrm{~min}$ from the beginning of the stabilization period up to $240 \mathrm{~min}$ after starting the test.

\section{Test 2 (GHRH/Arg-TRH)}

One hundred micrograms of GHRH-(1-44) were given iv at $0 \mathrm{~min}$. Thirty grams of Arg were administered in $500 \mathrm{~mL}$ saline from 120-150 min, followed by an injection of $200 \mu \mathrm{g} \mathrm{TRH}$, iv. Blood samples were drawn as described in test 1.

\section{Test 3 (GHRH/GHRH-Arg-TRH)}

One hundred micrograms of GHRH-(1-44) were injected iv at $0 \mathrm{~min}$. The volunteers received a second 100- $\mu$ g GHRH-(1-44) injection after $120 \mathrm{~min}$, immediately before starting the $30 \mathrm{~g}$ Arg infusion (over $30 \mathrm{~min}$ ). Two hundred micrograms of TRH were given iv after $150 \mathrm{~min}$. Blood samples were drawn as described in test 1 .

\section{Test 4 (GHRH-Arg-TRH)}

One hundred micrograms of GHRH-(1-44) were administered at 0 min, immediately followed by an infusion of $30 \mathrm{~g}$ Arg over $30 \mathrm{~min}$ and $200 \mu \mathrm{g} \mathrm{TRH}$, iv, thereafter. Blood samples were drawn $30 \mathrm{~min}$ before until 120 min after starting the test, at 15- and 30-min intervals.

\section{Test 5 (TRH)}

Two hundred micrograms of TRH were injected iv at $0 \mathrm{~min}$. Blood samples were drawn from $30 \mathrm{~min}$ before to $90 \mathrm{~min}$ after starting the test, at $15-$ and $30-\mathrm{min}$ intervals.

\section{Assays}

GH was measured by a commercially available IRMA [immunoradiometric assay, Medgenix (Medgenix Diagnostics, Ratingen, Germany); intraassay coefficients of variation (CVs), $4.5 \%$ and $3.9 \%$ for low and high concentrations, respectively; interassay CVs, $8.3 \%$ and $5.9 \%$ ). TSH was measured as previously described (10). The intraassay CVs were $5.9 \%$ and $7.7 \%$ for low and high concentrations, respectively; the interassay $\mathrm{CV}$ was $13 \%$. Serum samples for $\mathrm{GH}$ and TSH determinations were stored at $-20 \mathrm{C}$ until the time of assay.

\section{Statistical analysis}

All values are given as the mean $\pm \mathrm{sE}$. For statistical evaluation, baseline GH ( 0 or $120 \mathrm{~min}$ ) and maximum GH (45 or $165 \mathrm{~min}$ ) were compared by Student's $t$ test, and significance was corrected using the Bonferroni rule. The area under the GH curve (AUC) from 0-120 min was compared to the AUC from 120-240 min by ANOVA. The TSH AUC was evaluated up to $90 \mathrm{~min}$ after TRH injection using ANOVA. If ANOVA proved to be significant, further testing with paired Wilcoxon's rank test was performed. The results were considered significant at a level of $P \leq 0.05$.

\section{Results}

No serious side-effects were recorded after GHRH-(1-44) or TRH iv bolus injection or during any of the Arg infusions. 
Minor complaints were transient facial flushing soon after GHRH bolus administration and an urge to urinate immediately after TRH injection, which subsided within 3-5 min.

\section{Test 1}

After the first GHRH injection, the mean GH concentration of eight normal men increased significantly from $0.3 \pm 0.0$ $\mu \mathrm{g} / \mathrm{L}$ (mean $\pm \mathrm{sE}$ ) at $0 \mathrm{~min}$ to a maximum of $14.4 \pm 3.9 \mu \mathrm{g} / \mathrm{L}$ at 45 min (Fig. 2). Compared to this, the mean GH increase after the second GHRH injection at $120 \mathrm{~min}$ was significantly lower (from $4.5 \pm 1.6 \mu \mathrm{g} / \mathrm{L}$ to $5.6 \pm 1.6$ after $165 \mathrm{~min}$ ). The AUC of the GH response was also significantly lower $(P<$ $0.02)$ after the second stimulation $(0.5 \pm 0.1 \mathrm{~min} \cdot \mathrm{mg} / \mathrm{L}$ vs. 1.2 \pm 0.3 after the first GHRH stimulation).

\section{Test 2}

After Arg-TRH administration, the mean GH concentration increased significantly from $2.9 \pm 0.8 \mu \mathrm{g} / \mathrm{L}$ at $120 \mathrm{~min}$ to a maximum of $13.6 \pm 3.9 \mu \mathrm{g} / \mathrm{L}$ (Fig. 3) after $165 \mathrm{~min}$. There were no significant differences between the $\mathrm{GH}$ response to GHRH injected at $0 \mathrm{~min}$ (AUC, $0.9 \pm 0.2 \mathrm{~min} \cdot \mathrm{mg} / \mathrm{L}$ ) and that to Arg given $120 \mathrm{~min}$ after GHRH (AUC, $0.9 \pm 0.2 \mathrm{~min} \cdot \mathrm{mg}$ / L), as shown in Fig. 3.

\section{Test 3}

After another GHRH injection, followed by Arg-TRH administration, the mean $\mathrm{GH}$ level increased significantly from $6.3 \pm 3.0 \mu \mathrm{g} / \mathrm{L}$ at $120 \mathrm{~min}$ to a maximum of $30.3 \pm 6.8 \mu \mathrm{g} / \mathrm{L}$ (Fig. 4) at $165 \mathrm{~min}$. The AUC of the GH increase seen after the first GHRH injection at $0 \mathrm{~min}$ was $1.2 \pm 0.3 \mathrm{~min} \cdot \mathrm{mg} / \mathrm{L}$. Compared to this, the GH increase after combined GHRHArg administration (AUC, $1.9 \pm 0.4 \mathrm{~min} \cdot \mathrm{mg} / \mathrm{L}$ ) was significantly larger $(P<0.02)$, as shown in Fig. 4.

\section{Test 4}

After iv GHRH followed by immediate Arg infusion and TRH administration after $30 \mathrm{~min}$, the mean GH concentration increased significantly from $0.3 \pm 0.0 \mu \mathrm{g} / \mathrm{L}$ at $0 \mathrm{~min}$ to a

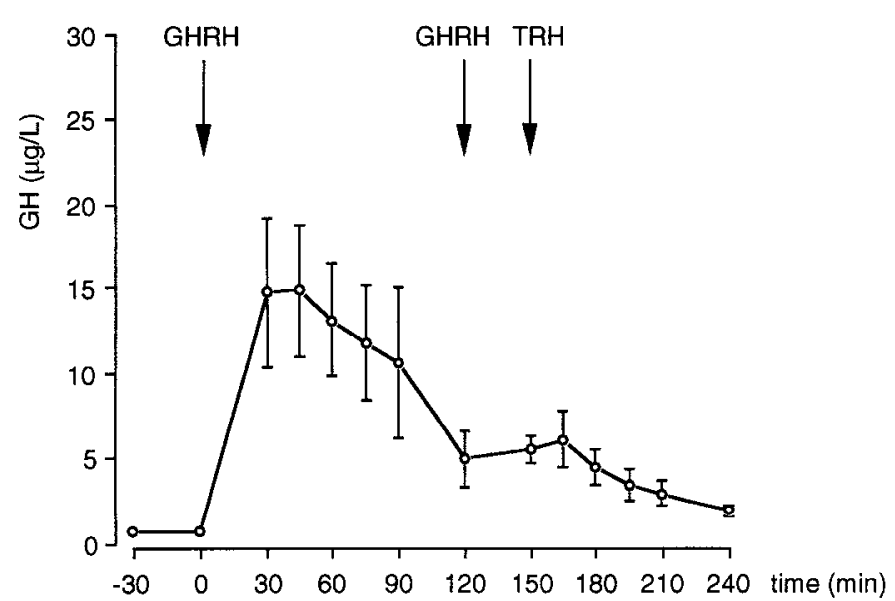

FIG. 2. Test 1 (GHRH/GHRH-TRH): mean GH levels before and after iv stimulation. Arrows indicate the times of GHRH ( 0 and $120 \mathrm{~min}$ ) and TRH (150 min) injections. The AUC of the GH response after the second GHRH injection was significantly lower than the AUC of the first GH increase $(P<0.02)$.

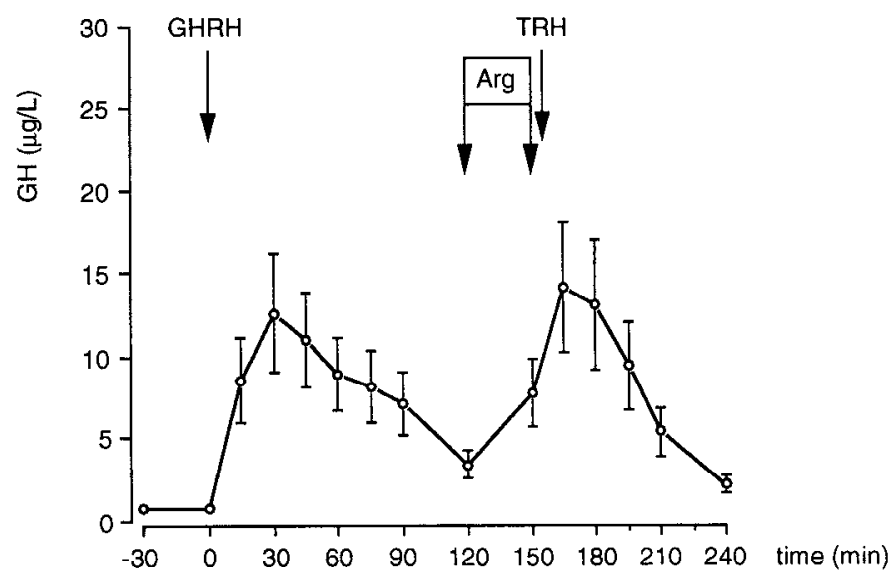

FIG. 3. Test 2 (GHRH/Arg-TRH): mean GH levels before and after iv stimulation. Arrows indicate the times of GHRH (0 min) and TRH $(150 \mathrm{~min}$ ) injections. Arg infusion was given after $120 \mathrm{~min}$ over 30 min. There were no significant differences in GH increase after GHRH injected at $0 \mathrm{~min}$ and that after Arg infusion at $120 \mathrm{~min}$.

maximum of $46.5 \pm 11.8 \mu \mathrm{g} / \mathrm{L}$ (Fig. 5) at $60 \mathrm{~min}$. The GH response $(P<0.02)$ to combined GHRH-Arg-TRH stimulation was significantly lower after previous GHRH injection (AUC, $1.9 \pm 0.4 \mathrm{~min} \cdot \mathrm{mg} / \mathrm{L}$ ) than after GHRH-Arg-TRH stimulation alone (AUC, $3.5 \pm 0.9 \mathrm{~min} \cdot \mathrm{mg} / \mathrm{L}$ ), as shown in Figs. 4 and 5.

Summing up the AUCs of tests 1 and 2 between $120-240$ min gives a result that is still significantly lower $(P<0.05)$ than the AUC of combined GHRH-Arg-TRH stimulation after previous GHRH injection (test 3), as shown in Figs. 2-4.

In test 4, the GHRH/Arg/TRH-stimulated TSH secretion (AUC, $537 \pm 181 \mathrm{~min} \cdot \mathrm{mU} / \mathrm{L}$ ) was significantly higher $(P \leq$ 0.02 ) than that after TRH alone (test $5,468 \pm 151 \mathrm{~min} \cdot \mathrm{mU} / \mathrm{L}$ ). In tests 1,2 , and 3 (AUC in test $1,565 \pm 228 \mathrm{~min} / \mathrm{mU} \cdot \mathrm{L}$; test $2,537 \pm 192$; test $3,490 \pm 143$ ), there was no significant

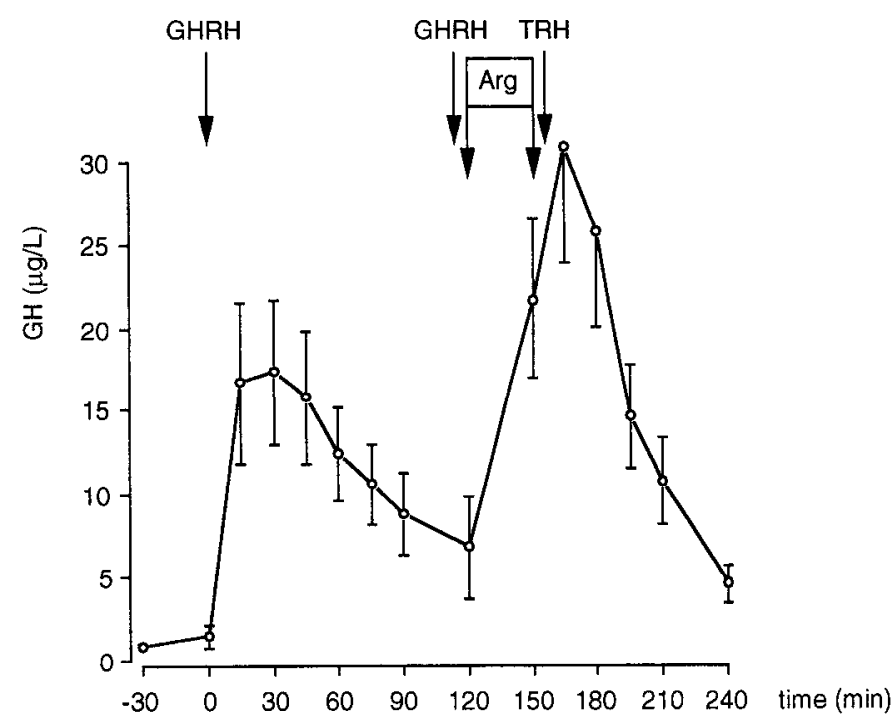

FIG. 4. Test 3 (GHRH/GHRH-Arg-TRH); mean GH levels before and after iv stimulation. Arrows indicate the times of GHRH ( 0 and 120 $\mathrm{min})$ and TRH (150 $\mathrm{min}$ ) injections. Arg infusion was given after 120 min over $30 \mathrm{~min}$. Compared to AUC after iv GHRH injection at $0 \mathrm{~min}$, GH release after combined GHRH/Arg/TRH stimulation was significantly greater $(P<0.02)$. 


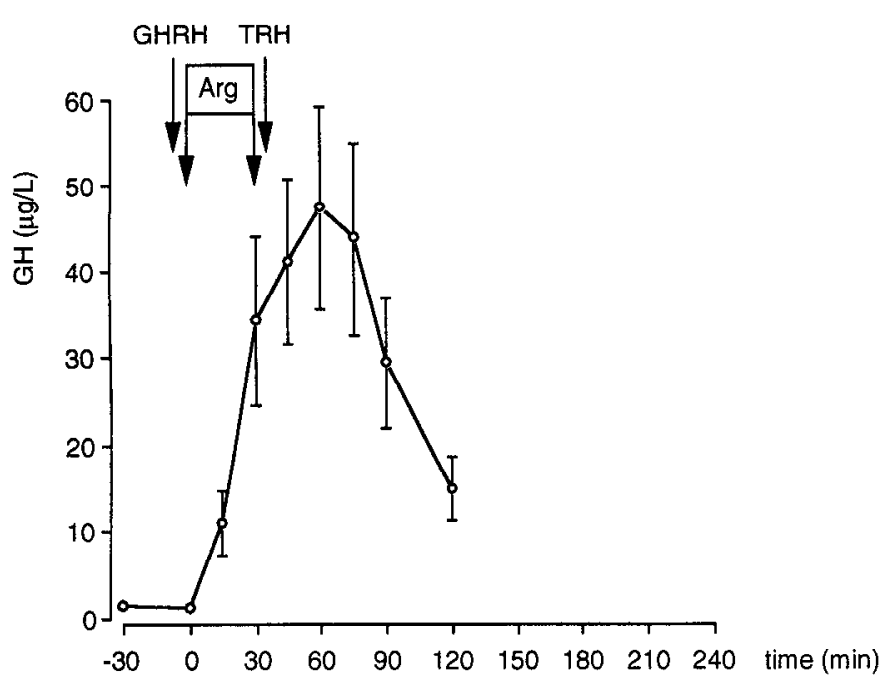

FiG. 5. Test 4 (GHRH-Arg-TRH): mean GH levels before and after iv stimulation. Arrows indicate the times of GHRH ( $0 \mathrm{~min})$ and TRH ( 30 $\mathrm{min}$ ) injections. Arg infusion was given over $30 \mathrm{~min}$, immediately after GHRH stimulation. Mean GH concentrations increased significantly, reaching a maximum at $60 \mathrm{~min}$.

difference in stimulated TSH secretion compared to that after TRH alone (test 5).

\section{Discussion}

The present report confirms that the mean GH response to a second GHRH injection is significantly lower than the first $\mathrm{GH}$ increase. These findings are in agreement with data presented by Losa et al. (6), who showed that intermittent stimulation of $\mathrm{GH}$ secretion with $50 \mu \mathrm{g}$ GHRH-(1-44) within $2 \mathrm{~h}$ as well as continuous stimulation by GHRH infusion over $2 \mathrm{~h}$ result in a decreased GH response in normal subjects. Shibasaki et al. (11) and Page et al. (12) described similar changes in plasma GH levels in normal men pretreated with $200 \mu \mathrm{g}$ GHRH-(1-44). To clarify the mechanism of persistent GHRH-induced GH hypersecretion, additional studies during 24-h GHRH infusion were performed $(13,14)$. Continuous sc infusions of GHRH increased GH peak frequency during both the day and the night, but mean GH levels and AUC increased only during the daytime hours (14). It was speculated that the decrease in nocturnal GH peak amplitude and the decreased $\mathrm{GH}$ response after short term repeated stimulation with GHRH may be due to either a depletion of the readily available GH pool or, alternatively, to hypothalamic somatostatin antagonizing GHRH-stimulated GH secretion $(6,14)$. Vance et al. (15) found an augmentation of naturally occurring GH pulses during continuous infusion of GHRH and concluded that these GH pulses are the result of GHRH secretion associated with a diminution or withdrawal of somatostatin secretion. Ross et al. (16) showed that GH may regulate its own secretion, probably at the hypothalamic or pituitary level, via changes in hypothalamic somatostatin secretion. The results observed by Shibasaki et al. (11) and Ghigo et al. (17) also suggested that a desensitization of GHRH receptors in somatotrophs and/or enhanced somatostatin release induced by an increase in GH levels after a previous GHRH injection may be involved in the mechanism by which the prior GHRH injection suppresses the GH re- sponse to the second GHRH bolus. Arg is known to stimulate GH secretion by suppression of hypothalamic somatostatin (9). We demonstrated that Arg administered together with GHRH led to higher serum GH levels than a single dose of GHRH or Arg alone and concluded that the stimulatory effect of Arg was mediated by suppression of endogenous hypothalamic somatostatin secretion (9). Further support of this hypothesis was given by Ghigo et al. in 1990 (18), who showed that both Arg and pyridostigmine induce a clear GH increase in children with familial short stature by the same mechanism, namely suppression of somatostatin release. These data in normal adults were confirmed in our study. In contrast, Magnan et al. (19) demonstrated a direct effect of neostigmine on hypothalamic GHRH release in rams and showed a synergistic effect of $\mathrm{GHRH}$ and neostigmine on $\mathrm{GH}$ secretion. These differences from human results are probably due to species differences and may be explained by the use of a nonmaximal GHRH stimulation dose in rams. Corresponding to the reports by Page et al. (12) and Ghigo et al. (17), we showed that after prior stimulation with GHRH, the second GH response (120 min) is not blunted when performed with Arg. Our findings also demonstrate that decreasing GH responses to a short term repeated GHRH bolus can be partially avoided by a combined stimulation with GHRH-Arg. The GH response to combined administration of GHRH-Arg after previous GHRH stimulation is even higher than the sum of the individual GH responses to GHRH only and Arg only, showing that Arg administration potentiates GH increase even after prior GHRH exposure. Without prior GHRH administration, this potentiation was significantly higher, which shows that suppression of hypothalamic somatostatin tonus by Arg could only partially restore the diminished GH response after prior GHRH stimulation or was not complete. This indicates that the decreased GH response after repeated GHRH administration may be partially induced by elevated somatostatin tonus and partially by exhaustion of the readily releasable GH pool.

Confirming our observations (9), Merola et al. (20) demonstrated that Arg infusion potentiates the TSH responsiveness to TRH in healthy subjects by antagonizing the inhibitory effect of somatostatin on TSH secretion (21). Although the TSH increase was significantly higher after stimulation in test 4 than after TRH alone, there was no significant difference between tests 2 and 3 , probably due to the small number of subjects and to interindividual fluctuations of the TSH response. Additionally, a blunting influence of long term GHRH stimulation on TRH-stimulated TSH (tests 1, 2, and 3) cannot be excluded, masking the effect of enhanced somatustatin tonus on stimulated TSH secretion.

In conclusion, we propose that a decreased GH response to repeated GHRH injection may be due to an elevated hypothalamic somatostatin secretion, which can be suppressed by $\mathrm{Arg}$, and to a limitation of the ready available $\mathrm{GH}$ pool in the human pituitary.

\section{References}

1. Reichlin S. 1960 Growth and the hypothalamus. Endocrinology. 67:760-773. 2. Sassolas G, Chatelain P, Cohen $R$, et al. 1984 Effects of human pancreatic tumor growth hormone-releasing hormone on immunoreactive and bioactive plasma growth hormone secretion in normal young men. J Clin Endocrinol Metab. 59:705-709. 
3. Thorner MO, Spiess J, Vance ML, et al. 1983 Human pancreatic growth hormone releasing factor selectively stimulates growth hormone secretion in man. Lancet. 1:24-28.

4. Shibasaki T, Shizume K, Masuda A, et al. 1984 Plasma growth hormonereleasing factor in acromegalic patients. J Clin Endocrinol Metab. 58:215-217.

5. von Werder K, Müller OA, Hartl R, Losa M, Stalla GK. 1984 Growth hormone releasing factor (hpGRF)-stimulation test in normal controls and acromegalic patients. J Endocrinol Invest. 7:185-191.

6. Losa M, Bock L, Schopohl J, Stalla GK, Müller OA, von Werder K. 1984 Growth hormone releasing factor infusion does not sustain elevated GH-levels in normal subjects. Acta Endocrinol (Copenh). 107:462-470.

7. Ceda GP, Hoffman AR. 1985 Growth hormone-releasing factor desensitization in rat anterior pituitary cells in vitro. Endocrinology. 116:1334-1340.

8. Patel YC, Wheatley T. 1983 In vitro and in vivo plasma disappearance and metabolism of somatostatin-28 and somatostatin-14 in the rat. Endocrinology. $112: 220-225$.

9. Alba-Roth J, Müller OA, Schopohl J, von Werder K. 1988 Arginine stimulates growth hormone secretion by suppressing endogenous somatostatin secretion. J Clin Endocrinol Metab. 67:1186-1189.

10. Bernutz C, Kewenig M Horn K, Pickardt CR. 1985 Detection of thyroid disorders by use of basal thyrotropin values determined with an optimized sandwich enzyme immunoassay. Clin Chem 31/2:289-292.

11. Shibasaki T, Hotta M, Masuda A, et al. 1985 Plasma responses to GHRH and insulin-indiced hypoglycemia in man. J Clin Endocrinol Metab. 60:1265-1267.

12. Page MD, Dieguez C, Valcavi R, Edwards C, Hall R, Scanlon MF. 1988 Growth hormone $(\mathrm{GH})$ responses to arginine and L-dopa alone and after GHRH pretreatment. Clin Endocrinol (Oxf). 28:551-558.

13. Gelato MC, Oldfield E, Loriaux DL, Merriam GR. 1990 Pulsatile growth hor- mone secretion in patients with acromegaly and normal men: the effects of growth hormone releasing hormone infusion. J Clin. Endocrinol Metab. 71:585-590.

14. Corpas E, Harman SM, Pineyro MA, Roberson R, Blackman MR. 1993 Continuous subcutaneous infusions of growth hormone (GH) releasing hormone 1-44 for 14 days increase $G H$ and insulin-like growth factor-I levels in old men. J Clin Endocrinol Metab. 76:134-138.

15. Vance ML, Kaiser DL, Evans WS, et al. 1985 Pulsatile growth hormone secretion in normal man during a continuous 24-hour infusion of human growth hormone releasing factor (1-40). J Clin Invest. 75:1584-1590.

16. Ross RJM, Borges F, Grossman A, et al. 1987 Growth hormone pretreatment in man blocks the response to growth hormone releasing hormone; evidence for a direct effect of growth hormone. Clin Endocrinol (Oxf). 26:117-123.

17. Ghigo E, Arvat E, Valente F, et al. 1991 Arginine reinstates the somatotrope responsiveness to intermittent growth hormone-releasing hormone administration in normal adults. Neuroendocrinology. 54:291-294.

18. Ghigo E, Bellone J, Mazza E, et al. 1990 Arginine potentiates the GHRH- but not the pyridostigmine-induced GH secretion in normal short children. Further evidence for a somatostatin suppressing effect of arginine. Clin Endocrinol (Oxf). 32:763-767.

19. Magnan E, Cataldi M, Guillaume V, et al. 1993 Neostigmine stimulates growth hormone-releasing hormone release into hypophysial portal blood of conscious sheep. Endocrinology. 132:1247-1251.

20. Merola B, Colao A, Cataldi M, et al. 1992 Serum thyrotropin response to combined arginine and thyrotropin-releasing hormone administration provides evidence for an altered somatostatinergic tone in acromegaly. Horm Res. 37:7-13.

21. Tanjasiri P, Kozbur X, Florsheim W. 1976 Somatostatin in the physiologic control of thyrotropin secretion. Life Sci. 19:657-660. 